\title{
The Role of Pharmacists in Optimizing Molecular Testing with Evolving Biomarkers and Treatment for Non-Small Cell Lung Cancer
}

\author{
${ }^{1}$ Ashique Ahmed, ${ }^{2}$ Alakesh Bharali, ${ }^{1}$ Arindam Dutta, ${ }^{1}$ Abhinab Chetia, \\ ${ }^{1}$ Arzoo Newar, ${ }^{1}$ Bedanta Bhattacharjee, ${ }^{1}$ Bhargab Deka $*,{ }^{1}$ Bonti Sonowal, \\ ${ }^{1}$ Bharjil Bingari, ${ }^{1}$ Dhunusmita Barman, ${ }^{1}$ Dibyojyoti Sarmah, ${ }^{1}$ Farida Pegu, \\ ${ }^{1}$ Farak Ali, ${ }^{3}$ Gargi Das, ${ }^{4}$ Himangshu Sarma, ${ }^{1}$ Nikita Dey, ${ }^{2}$ Nayanika Neog, \\ ${ }^{1}$ Pinkan Sadhukan, ${ }^{1}$ Rofiqul Islam, ${ }^{1}$ Richa Sonowal, ${ }^{1}$ Shahnaz Alom, \\ ${ }^{5}$ Shamima Nasreen Ahmed, ${ }^{2}$ Taslima Akhter Rohman \\ ${ }^{1}$ Department of Pharmaceutical Sciences, Faculty of Science and Engineering, Dibrugarh \\ University, Dibrugarh-786004, Assam, India. \\ ${ }^{2}$ Department of Pharmacy, Girijananda Chowdhury Institute of Pharmaceutical Sciences- \\ 781017, Guwahati, Assam, India. \\ ${ }^{3}$ Department of Pharmacy, Himalayan Pharmacy Institute, Majhitar, East Sikkim-737136, \\ Sikkim, India. \\ ${ }^{4}$ Life Sciences Division, Institute of Advanced Study in Science and Technology, Guwahati- \\ 781035, Assam, India. \\ ${ }^{5}$ Karnataka College of Pharmacy, Hegde Nagar, Bengaluru- 560064, Karnataka, India.
}

\begin{abstract}
Molecular testing and the development of targeted therapies have revolutionized the treatment of non-small cell lung cancer (NSCLC). Despite the advantages of molecular testing in patients with NSCLC and guideline recommendations, there is no specific standard testing method, resulting in variable testing practices based on institution protocol and access. Pharmacists can help to improve coordination of care around appropriate testing as results are important in determining the most appropriate targeted treatment course. The majority of patients with NSCLC are tested for PD-L1, EGFR, ALK, ROS1, and BRAF mutations. These biomarkers and their corresponding targeted therapies are more understood than the remaining biomarkers, such as KRAS, RET, MET exon 14 (METex14), and NTRK. Multiple new and emerging therapies target these latter biomarkers, and this article will focus on these lesser-known biomarkers. As the treatment of NSCLC becomes increasingly biomarker-driven and more therapies are added to the armamentarium for the management of NSCLC, pharmacists will be called upon to assist the oncology care team to optimize NSCLC treatment to improve patient outcomes. (Keywords: Lung cancer; biomarker; oncology pharmacists; molecular testing)
\end{abstract}




\section{Introduction}

In the United States, lung cancer is becoming the leading cause of cancer fatalities in both men and women [1]. The low survival rate of lung cancer is mostly due to the fact that by the time patients are diagnosed, half of them are already in an advanced stage of the disease. The US Preventive Services Task Force drafted revised screening recommendations in 2020 in an attempt to diagnose more patients at an earlier stage of lung cancer when disease cure is a possibility; however, more effective and tolerable therapies for the advanced disease remain an urgent need [2].

Patients with lung cancer may present with cough, hemoptysis, dyspnoea, weight loss, or chest pain, or a tumor may be suspected based on screening computed tomography scan or incidentally discovered on imaging performed for another reason [3]. The diagnostic approach should be individualized based on tumor size and location, presence of mediastinal or distant disease, patient comorbidities, and local expertise. Some patients will undergo initial surgical excision and others a biopsy. Immunohistochemical staining is used to make a diagnosis of non-small cell lung cancer (NSCLC) and determine if the tumor is an adenocarcinoma, squamous cell, adenosquamous carcinoma, large cell carcinoma, carcinoid type, or a less common subtype [3]. Adenocarcinoma is the most common subtype and numerous genetic variants have been identified that drive therapy selection [4]. Tissue should be preserved for biomarker testing for patients with NSCLC. Approximately $40 \%$ to $45 \%$ of adenocarcinoma NSCLC tumors have mutations with targeted therapies currently available and an additional $25 \%$ of tumors express KRAS mutations. However, these numbers do not include NSCLC mutations of unknown clinical significance or mutations that are still unknown and could yield future directions for treatment. Table 1 summarizes the various genes and proteins that are being targeted to treat non-small cell lung cancer [5].

Table 1. Genes and proteins targeted in the treatment of non-small cell lung cancer

\begin{tabular}{|c|c|c|c|}
\hline Abbreviation & Gene/ Protein & Frequency & Meaning \\
\hline$E G F R$ & $\begin{array}{l}\text { Epidermal } \\
\text { growth factor } \\
\text { receptor }\end{array}$ & $17-32 \%$ & $\begin{array}{l}\text { Both a gene and its } \\
\text { receptor tyrosine kinase. } \\
\text { also known as ERBBl }\end{array}$ \\
\hline$K R A S$ & $\begin{array}{l}\text { Kirsten rat } \\
\text { sarcoma viral } \\
\text { oncogene } \\
\text { homolog }\end{array}$ & $20-30 \%$ & $\begin{array}{l}\text { A gene that encodes the } \\
\text { K-Ras protein as part of } \\
\text { the RAS/MAPK } \\
\text { pathway. }\end{array}$ \\
\hline$A L K$ & $\begin{array}{l}\text { Anaplastic } \\
\text { lymphoma kinase }\end{array}$ & $3-13 \%$ & $\begin{array}{l}\text { Both a gene and its } \\
\text { receptor tyrosine kinase. }\end{array}$ \\
\hline
\end{tabular}


European Journal of Molecular \& Clinical Medicine

ISSN 2515-8260 Volume 08, Issue 03, 2021

\begin{tabular}{|c|c|c|c|}
\hline$M E T$ & $\begin{array}{l}\text { Mesenchymal- } \\
\text { epithelial } \\
\text { transition factor }\end{array}$ & $2-5 \%$ & $\begin{array}{l}\text { Both a gene and its } \\
\text { receptor tyrosine kinase. } \\
\text { also known as c-Met. }\end{array}$ \\
\hline$R E T$ & $\begin{array}{l}\text { Rearranged } \\
\text { during } \\
\text { transfection }\end{array}$ & $1.2-2 \%$ & $\begin{array}{l}\text { Both a gene and its } \\
\text { receptor tyrosine kinase. } \\
\text { it technically is an } \\
\text { abbreviation for } \\
\text { "rearranged during } \\
\text { transfection". }\end{array}$ \\
\hline$B R A F$ & $\begin{array}{l}\text { v-Raf murine } \\
\text { sarcoma viral } \\
\text { oncogene } \\
\text { homolog B }\end{array}$ & $1-3 \%$ & $\begin{array}{l}\text { A gene that encodes the } \\
\text { B-Raf protein, with } \\
\text { V600E the most } \\
\text { effectively targeted } \\
\text { oncogenic mutation. }\end{array}$ \\
\hline ROS7 & Cross oncogene 1 & $1-2 \%$ & $\begin{array}{l}\text { Both a gene and its } \\
\text { receptor tyrosine kinase }\end{array}$ \\
\hline NTRK & $\begin{array}{l}\text { Neurotrophic } \\
\text { tyrosine receptor } \\
\text { kinase }\end{array}$ & $0.2 \%$ & $\begin{array}{l}\text { NTRK7, NTRK2, NTRK3 } \\
\text { genes encode tropomyosin } \\
\text { receptor kinases (TRKA, } \\
\text { TRKB, TRKC). }\end{array}$ \\
\hline HER2 & $\begin{array}{l}\text { Human } \\
\text { epidermal growth } \\
\text { factor }\end{array}$ & $2-9 \%$ & $\begin{array}{l}\text { Both a gene and its } \\
\text { receptor tyrosine kinase. } \\
\text { also known as ERBB2 }\end{array}$ \\
\hline$N R G 7$ & Neuregulin 1 & $0.2 \%$ & $\begin{array}{l}\text { Both a gene and a cell } \\
\text { adhesion molecule that } \\
\text { interacts with the ERBB } \\
\text { receptor tyrosine kinases }\end{array}$ \\
\hline$M E K$ & $\begin{array}{l}\text { Mitogen- } \\
\text { activated protein } \\
\text { kinase }\end{array}$ & $1 \%$ & $\begin{array}{l}\text { Proteins (MEKl and } \\
\text { MEK2) that are part of } \\
\text { the MAPK pathway. }\end{array}$ \\
\hline
\end{tabular}

More than 20 therapies targeting 8 different biomarkers are currently recommended by the National Comprehensive Cancer Network (NCCN) guidelines panel for the management of metastatic NSCLC. The incorporation of targeted and immunotherapies in the management of metastatic NSCLC is credited for an improvement in the 5-year survival of patients from $25 \%$ 
to up to $50 \%$ in patients who are eligible for targeted therapies, with variation reflecting the tumor biomarker present [6].

\section{Biomarker Testing}

A biomarker is considered predictive if there is an association between the biomarker, a specific therapy, and patient outcome [7]. A prognostic biomarker reflects an association between patient survival and the biomarker that is independent of treatment received because the biomarker reflects innate tumor behavior. Currently, KRAS is considered a prognostic biomarker, whereas sensitizing EGFR mutations, the $A L K$ fusion oncogene, ROS1 gene fusions, NTRK gene fusions, RET rearrangements, METex14 skipping mutations, BRAF V600E point mutations, and programmed cell death protein ligand 1 (PD-L1) expression are predictive biomarkers [8].

\subsection{Biomarker Testing Strategies}

Biomarker testing recommendations in NSCLC are rapidly evolving. The College of American Pathologists (CAP), the International Association for the Study of Lung Cancer (IASLC), and the Association for Molecular Pathology (AMP) updated their 2013 guidelines for molecular testing used to guide targeted therapy of NSCLC in 2018 [9]. This guideline was endorsed with a few modifications by the American Society of Clinical Oncology (ASCO) later that year [10]. The current version of the NCCN guidelines endorses testing for a broader array of biomarkers that reflects current research. The NCCN guidelines panel recommends a minimum of the following biomarkers be tested for all patients with metastatic, nonsquamous NSCLC: EGFR mutations, BRAF mutations, ALK fusions, ROS1 fusions, NTRK gene fusions, RET rearrangements, METex14 skipping mutations, and PD-L1 expression [11]. These somatic (spontaneously originating) mutations are generally considered mutually exclusive, with just $1 \%$ to $3 \%$ of NSCLC tumors harboring concurrent mutations. Patient factors such as smoking status, ethnicity, and histology are associated with specific genetic variants; however, these features should not be used to select patients for testing [12]. Targeted therapies directed at all biomarkers included in broad molecular profiling are not currently approved by the FDA; however, testing is still recommended because patients may be directed to clinical trials based on the molecular profile [13].

Several methods may be employed to determine biomarker expression. The NCCN guidelines panel recommends that testing be done at an accredited laboratory that meets Clinical Laboratory Improvement Amendment standards for accreditation [14]. Biomarker testing methods include next-generation sequencing (NGS), multiplex polymerase chain reaction (PCR), immunohistochemistry (IHC), and fluorescence in situ hybridization (FISH). The NCCN guidelines panel does not endorse any specific commercially available biomarker assay. Table 2 outlines the most common biomarker testing assays [15]. 
European Journal of Molecular \& Clinical Medicine

ISSN 2515-8260 Volume 08, Issue 03, 2021

Table 2. Review of common assays for biomarker testing

\begin{tabular}{|c|c|c|c|c|c|c|}
\hline \multirow[b]{2}{*}{$\begin{array}{l}\text { Molecular } \\
\text { Methods }\end{array}$} & \multicolumn{6}{|c|}{ Variant Types } \\
\hline & $\begin{array}{l}\text { Point } \\
\text { Mutations }\end{array}$ & $\begin{array}{l}\text { Small } \\
\text { Deletion, } \\
\text { Insertion }\end{array}$ & \begin{tabular}{|l} 
Copy \\
Number \\
Alterations
\end{tabular} & $\begin{array}{l}\text { Rearrange } \\
\text { ments }\end{array}$ & $\begin{array}{l}\text { Sensitivit } \\
\mathbf{y}(\%)\end{array}$ & $\begin{array}{l}\text { Turnaround } \\
\text { time }\end{array}$ \\
\hline Sizing assays & $+/-$ & $\checkmark$ & & & & 3 to 4 days \\
\hline $\begin{array}{l}\text { PCR and Sanger } \\
\text { sequencing }\end{array}$ & $\checkmark$ & $\checkmark$ & & & $20-50$ & 3 to 4 days \\
\hline $\begin{array}{l}\text { PCR and } \\
\text { pyrosequencing }\end{array}$ & $\checkmark$ & $+/-$ & & & $20-50$ & 3 to 4 days \\
\hline $\begin{array}{l}\text { PCR and mass } \\
\text { spectrometry }\end{array}$ & $\checkmark$ & $+/-$ & & & $1-10$ & 3 to 4 days \\
\hline $\begin{array}{l}\text { PCR and } \\
\text { single-base }\end{array}$ & $\checkmark$ & & & & $1-10$ & 3 to 4 days \\
\hline $\begin{array}{l}\text { qPCR and } \\
\text { digital PCR }\end{array}$ & $\checkmark$ & $\checkmark$ & & $\checkmark$ & 0.00001 & $\begin{array}{l}2 \text { to } 3 \\
\text { days }\end{array}$ \\
\hline $\begin{array}{l}\text { Allele-specific } \\
\text { PCR }\end{array}$ & $\checkmark$ & & & & & 1 to 2 days \\
\hline FISH & & & $+/-$ & $\checkmark$ & $<1$ & $\begin{array}{l}2 \text { to } 3 \\
\text { days }\end{array}$ \\
\hline $\begin{array}{l}\text { NGS: targeted } \\
\text { amplicon } \\
\text { capture }\end{array}$ & $\checkmark$ & $\checkmark$ & & & $1-10$ & 7-10 days \\
\hline $\begin{array}{l}\text { NGS: targeted } \\
\text { hybridization } \\
\text { capture }\end{array}$ & $\checkmark$ & $\checkmark$ & $\checkmark$ & $+/-1$ & $1-5$ & 15-20 days \\
\hline $\begin{array}{l}\text { NGS: whole- } \\
\text { exome }\end{array}$ & $\checkmark$ & $\checkmark$ & $\checkmark$ & $+/-1$ & Va riable & Weeks \\
\hline $\begin{array}{l}\text { NGS: whole } \\
\text { genome }\end{array}$ & $\checkmark$ & $\checkmark$ & $\checkmark$ & $\checkmark$ & Va riable & Weeks \\
\hline
\end{tabular}

PCR: polymerase chain reaction; qPCR: quantitatve PCR; FISH: fluorescent in situ hybridization. 


\subsubsection{Next-Generation Sequencing (NGS)}

Massively parallel or NGS is a broad molecular profiling technique that detects panels of mutations and gene fusions as well as copy number variations [16]. It is important to note that NGS represents a type of testing platform and individual NGS assays will detect different genes and abnormalities depending on the design of the NGS assay. NGS is the preferred testing method when it is available to the patient and adequate tissue is obtainable [17]. Testing with ribonucleic acid (RNA)-based NGS should be considered in patients with NSCLC that do have identifiable mutations on deoxyribonucleic acid (DNA)-based NGS, especially in never smokers, as RNA-based NGS will also detect fusion events [18]. In clinical practice, targeted NGS panels are preferred over whole-exome or whole-genome testing because they provide higher coverage of genomic regions of interest in an adequate time frame $[19,20]$.

\subsubsection{Real-time PCR (RT-PCR)}

Another type of mutation screening assay that detects multiple biomarkers simultaneously is RT-PCR [21]. In general, RT-PCR does not detect gene fusions (e.g. ROS1 and ALK mutations are gene fusion events). The Mass ARRAY and SNaPshot Multiplex System are examples of RT-PCR assays [22]. While RT-PCR can detect more than 50 point mutations, it detects fewer biomarkers than NGS panels[23].

\subsubsection{Sanger Sequencing}

Sanger sequencing refers to DNA sequencing by capillary electrophoresis. Although this testing was previously the gold standard, the ability to sequence only 1 gene at a time now limits its use. If a sample has fewer than $25 \%$ to $30 \%$ tumor cells, tumor enrichment methodologies should be used with Sanger sequencing[24].

\subsubsection{Immunohistochemistry (IHC)}

The expression of the gene as assessed by IHC may be used as a surrogate for fusion testing in some scenarios[25]. The CAP/IASLC/AMP guidelines indicate the performance of IHC is suboptimal for EGFR mutations; however, the use of $A L K$ IHC is equivalent to FISH for routine biomarker assessment. IHC is also used to determine PD-L1 expression[26].

\subsubsection{Fluorescent in situ Hybridization (FISH)}

Targeted gene amplification, copy number, and/or rearrangement is often assessed by FISH. Despite the availability of targeted therapies directed at specific biomarkers and broad endorsement of biomarker testing in multiple guidelines, there is variable uptake for biomarker testing in clinical practice [26]. Rates of biomarker testing have improved in recent years for $E G F R, A L K$, and $R O S 1$ with reports of testing before therapy initiation in $88 \%$ to $100 \%$ of patients. Barriers to testing may include inadequate sample size and the need for rebiopsy to obtain adequate tissue; lack of payer coverage of testing; and performance of tests as single-gene tests rather than a broad panel assay [27]. In 2018, the Centres for Medicare \& Medicaid Services (CMS) approved a national coverage decision for NGS testing in patients with recurrent, relapsed, refractory, metastatic, or advanced stages III or IV cancer who had not been previously tested using the same NGS test and decided to seek further cancer treatment [28]. The NCCN guidelines panel recommends that an adequate volume of tissue be obtained for both diagnosis and molecular testing and a strategy of rapid on-site evaluation during biopsy may be used to ensure specimens are adequate for molecular testing [11]. Another strategy to improve the rate of testing is the use of reflex testing rather than waiting 
for a physician's order. Ensuring biomarker testing has analytical validity, discerns an appropriate magnitude of difference for an endpoint of value, and is backed by a high level of evidence will facilitate adoption by both payers and clinicians alike [29].

The FDA maintains a website of tests cleared or approved by the Centre for Devices and Radiological Health to analyze variations in the sequence, structure, or expression of DNA and RNA to diagnose a disease or medical conditions, infection with an identifiable pathogen, or determine genetic carrier status[30]. Currently, the Oncomine Dx Target Test is the only NGS biomarker assay approved by the FDA for use in patients with NSCLC to detect single-nucleotide variants and deletions in multiple genes from DNA (e.g. $A L K, B R A F$, $E G F R, E R B B 2, K R A S, M E T$, and RET) and fusions in ROS1 from RNA [31].

\section{Personalized Pharmacotherapy}

The management of NSCLC has changed significantly in the past few years with the presence or absence of biomarkers now guiding the treatment approach. The platinum-based doublet therapy that was standard of care for decades is now reserved for patients without driver mutations who are not candidates for immunotherapy [3, 32, 33]. The majority of patients with NSCLC are tested for PD-L1, EGFR, ALK, ROS1, and BRAF mutations [15, 34]. Patients with advanced, nonsquamous NSCLC who lack driver mutations and are candidates for immunotherapy should have PD-L1 testing completed. Patients with high PD-L1 expression (>50\% tumor proportion score [TPS]), nonsquamous histology, and performance status of 0 to 1 are candidates for single-agent atezolizumab or pembrolizumab [3, 33]. Similar patients with rapidly progressive disease may be offered platinum doublet therapy with immunotherapy. Patients with negative (TPS 0\%) and low positive PD-L1 expression (TPS 1\%-49\%), nonsquamous histology, and performance status of 0 to 1 , who are eligible for chemoimmunotherapy should be offered a regimen such as carboplatin, pemetrexed, and pembrolizumab or another NCCN-recommended regimen, as determined by patient-specific factors [35]. Patients with advanced NSCLC with driver mutations should be offered therapy based on those mutations, as survival rates with targeted treatments for these patients are superior to that of chemotherapy/chemoimmunotherapy. Given many clinicians are familiar with therapies targeting EGFR, ALK, ROS1, and BRAF, the remainder of this article will focus on biomarkers with recently approved therapies and those currently under review by the FDA for NSCLC [36].

Figure 1: NSCLC treatment based on biomarkers

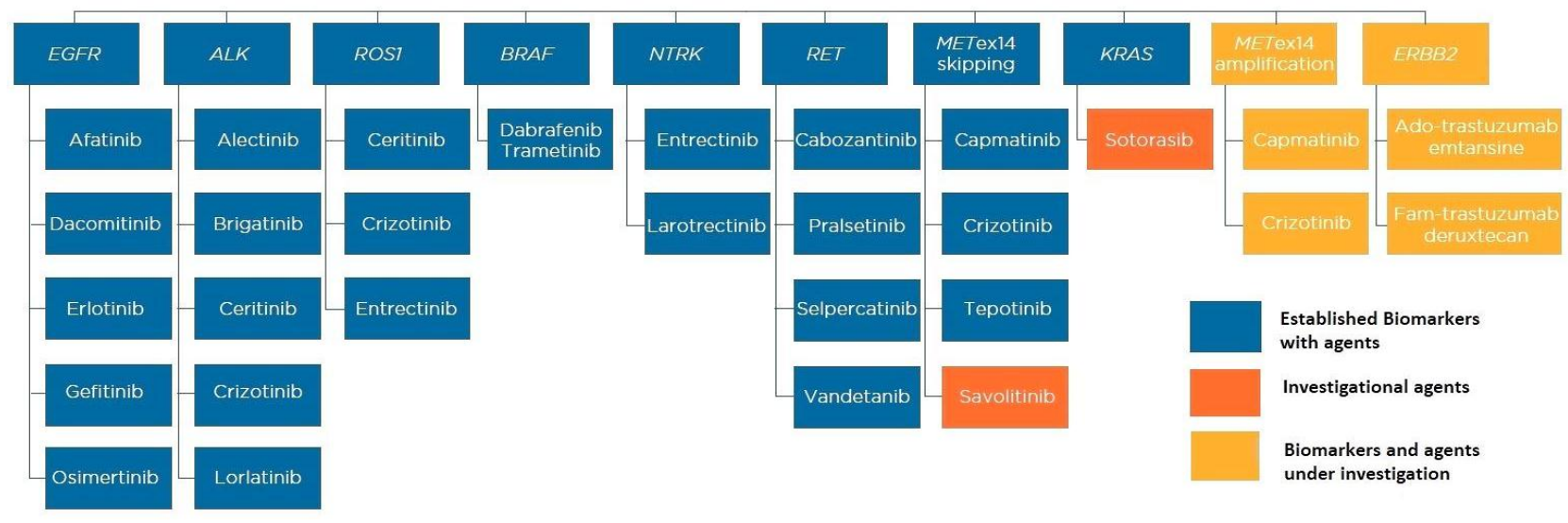


ISSN 2515-8260 Volume 08, Issue 03, 2021

\subsection{METex14 Skipping Mutations}

The MET gene encodes for the hepatocyte growth factor receptor (HGFR). MET activation promotes cell survival, proliferation, motility, invasion, and epithelial-mesenchymal transition [12]. There are 3 primary types of MET mutations: (a) amplification resulting in high expression of the receptor; (b) tyrosine kinase domain mutations resulting in constitutive activation of the receptor; (c) splicing mutations resulting in skipping of exon 14 and loss of Y1003, a binding site required for the ubiquitin-mediated degradation of the protein [37]. While oncogenesis can be driven by each of these mechanisms, the type of MET mutation a patient possesses determines which therapies can be used. For example, capmatinib, tepotinib, and savolitinib are indicated for use against METex14 skipping mutations [38]. METex14 skipping mutations occur in 3\% to $4 \%$ of patients with NSCLC and are associated with a poor prognosis. METex 14 mutations are more frequently observed in patients older than 70 years, those who smoke, and those with a sarcomatoid histology [39]. NGS-based assays interrogating MET as part of a wider gene panel are preferred for detecting MET mutations [40].

Capmatinib received FDA approval in adult patients with metastatic NSCLC and a METex14 skipping mutation, based on a prospective, open-label, multiple-cohort, phase 2 study of 364 patients with advanced NSCLC with a METex14 skipping mutation or MET amplification [41, 42]. The overall response rate (ORR) in patients with advanced NSCLC with a METex14 skipping mutation treated with capmatinib was $41 \%$; the median progression-free survival (PFS) was 5.4 months in previously treated patients and 12.4 months in treatment-naïve patients [42]. In patients with $M E T$ amplification, response rates ranged from $7 \%$ to $12 \%$ in patients who had tumor tissue with a gene copy number of less than 4 versus 6 to 9 , respectively. Gene copy number refers to the number of repeated genome sequences (ie, the higher the copy number, the more copies of $M E T$ are present to inhibit). The MET gene amplification cohorts were closed for futility at the interim analysis. The most common adverse effects (AEs) included edema (51\%), nausea (45\%), vomiting $(28 \%)$, increased creatinine (24\%), dyspnea (23\%), and fatigue (22\%). The FoundationOne CDx assay is the approved companion diagnostic test for capmatinib [43].

Crizotinib is a multikinase inhibitor with activity against $A L K$ and ROS1 mutations, as well as MET mutations. While it is not FDA approved for patients with NSCLC with a METex 14 skipping mutation, it is recommended by the NCCN guidelines panel for use in this setting. In a prospective cohort of 65 patients with METex14-altered NSCLC, 32\% of patients had an objective response to crizotinib; the median PFS was 7.3 months. The most common AEs included edema (51\%), vision disorder (45\%), nausea (41\%), diarrhea (39\%), and vomiting (29\%). Notably, none of the patients in this study had high levels of MET amplification as based on gene copy number [44].

Tepotinib, an inhibitor that targets METex14 skipping mutations, was approved in February 2021 [45]. Paik et al. presented results of 99 patients with metastatic NSCLC with a METex14 skipping mutation with at least 9 months of follow-up in the VISION study, a phase 2 cohort study of tepotinib [46]. The investigators reported an objective response rate of $46 \%$ and median PFS of 8.5 months in patients with a liquid-biopsy or combined liquidtissue biopsy and 11 months in the tissue biopsy group. A response rate of 55\% was observed in 11 patients with brain metastases. Similar to other MET inhibitors, common AEs included 
edema (63\%), nausea (26\%), diarrhea (22\%), and increased creatinine (18\%) [47].

Savolitinib is another kinase inhibitor that targets the METex14 skipping mutation and is under clinical investigation. It has been studied in combination with osimertinib in 18 patients in the phase $1 \mathrm{~b}$ TATTON study. The objective response rate was $44 \%$ for the combination therapy, with nausea (67\%), rash (56\%), and vomiting (50\%) as the most frequently reported AEs [48].

\subsection{Neurotrophic Receptor Tyrosine Kinase (NTRK) Gene Fusion}

The NTRK genes (NTRK1, NTRK2, NTRK3) encode for the synthesis of the tropomyosin receptor kinase (TRK) proteins TRKA, TRKB, and TRKC, which help to regulate pain, proprioception, appetite, and memory [49]. NTRK fusions are present in approximately $0.2 \%$ of solid tumors and function as driver oncogenesis. NTRK fusions do not display a predisposition for a subtype of NSCLC, gender, or smoking status. NTRK fusions may be identified by NGS, RT-PCR, or FISH [50].

Two NTRK inhibitors, larotrectinib, and entrectinib, are approved by the FDA for use in patients with solid tumors expressing NTRK gene fusions [51, 52]. Larotrectinib was evaluated in a phase 1 study in 55 adult and pediatric patients with a variety of solid tumors with an NTRK fusion, including 4 patients with lung cancer. An ORR of $80 \%$ was observed, with $16 \%$ of patients demonstrating a complete response. With a median follow-up of 9.9 months, the median PFS has not been reached; after 1 year of follow-up, 55\% of patients remained progression-free on larotrectinib. Frequently reported treatment-related AEs of larotrectinib include increased liver enzymes (38\%), dizziness (25\%), nausea (16\%), fatigue (16\%), and constipation (16\%) [53].

Entrectinib is approved by the FDA in both patients with a tumor expressing NTRK gene fusion and adult patients with metastatic NSCLC whose tumors are ROS1-positive [54]. Approval in patients with $N T R K$ tumors was based on a combined analysis of 3 ongoing phase 1 or 2 clinical trials of 54 adult patients with advanced or metastatic NTRK gene fusion-positive tumors. Ten patients with NSCLC were included in the study. With a median follow-up of 12.9 months, $57 \%$ of patients had an objective response to entrectinib, including 4 patients with a complete response; the median PFS was 11.2 months. In the overall safety population $(\mathrm{n}=355)$, the most frequently reported grade 3 to 4 AEs were anemia $(11 \%)$, increased weight (7\%), dyspnea (6\%), and fatigue (4\%) [55].

On-target AEs of NTRK inhibitors is related to the role of the TRK pathway in appetite, balance, and pain perception. In a review of 96 patients treated with a TRK inhibitor, Liu et al. described the incidence, presentation, and management of these AEs. Weight gain greater than $5 \%$ of body weight was observed in $53 \%$ of patients and approximately $10 \%$ of all patients have been prescribed a medication to mitigate weight gain. Dizziness, described as positional light-headedness, imbalance, or vertigo, was reported in $41 \%$ of patients. The most effective strategy to manage dizziness was dose reduction; pharmacotherapy with meclizine led to symptom improvement in about half of patients. Patients with orthostatic hypotension benefited from midodrine and/or fludrocortisone. Paresthesias were reported in $18 \%$ of patients, most often involving a perioral distribution and/or "sunburn" sensation; symptoms generally improved after the first month of therapy. Lastly, withdrawal pain, described as full-body ache, muscle pain, and/or allodynia was observed in approximately one-third of patients. Withdrawal pain was reported with both temporary and permanent discontinuation. 
Pain persisted between 10 and 26 days in patients permanently discontinuing therapy. Approximately half of the patients were given opioid or non-opioid therapy to manage withdrawal pain; however, it was helpful in just $23 \%$ of patients. Gradual tapering of NTRK inhibitors over 4 weeks may be beneficial in patients who experience withdrawal pain. Other less common neurologic AEs include cognitive impairment, mood disorders, sleep disturbance, and dysarthria [56].

\subsection{Rearranged During Transfection (RET) Fusion}

The RET proto-oncogene encodes for the development of a receptor tyrosine kinase that facilitates normal embryonic development [57]. In healthy tissue, RET plays a key role in renal and nervous system development [39]. Variants leading to RET fusion are observed in $1.2 \%$ to $2 \%$ of patients with adenocarcinoma NSCLC. RET fusions result in constitutively active, ligand-independent tyrosine kinase signaling and oncogenesis. RET fusion is observed more frequently in patients who have never smoked compared with those who have. RET fusions may be identified by NGS, RT-PCR or FISH [12].

Selpercatinib and pralsetinib are recommended as first-line therapy in patients who test positive for RET rearrangement in metastatic NSCLC [14]. Both are preferred over cabozantinib and vandetanib, which are less selective, multikinase inhibitors. Selpercatinib was evaluated in a phase $1 / 2$ trial in 105 patients with RET fusion-positive NSCLC who had previously received platinum-based chemotherapy and 39 previously untreated patients; the ORR was $64 \%$ and median PFS was 16.5 months in previously treated patients [58]. With a medium follow-up of 9.2 months, the median PFS was not evaluable in previously untreated patients receiving selpercatinib where an ORR of $85 \%$ was observed. Selpercatinib does penetrate the central nervous system and $91 \%$ of 11 patients with measurable lesions had an objective intracranial response with a median duration of response of 10.1 months. Selpercatinib received accelerated approval in May 2020 for adult patients with metastatic, RET fusion-positive NSCLC. The most frequent treatment-related AEs reported with selpercatinib include xerostomia (36\%), diarrhea (25\%), hypertension (17\%), and increased liver enzymes (22\%). Selpercatinib is associated with QTc prolongation, creating a need for close evaluation of concomitant medications [59].

Pralsetinib was approved by the FDA in September 2020 for adult patients with metastatic RET fusion-positive NSCLC as detected by an FDA-approved test [60]. Currently, the only approved test is the Oncomine Dx Target Test [61]. Pralsetinib was evaluated in a phase 1/2, nonrandomized, open-label, single-arm, multicohort, multicenter clinical trial in 80 patients with RET fusion-positive NSCLC who had previously received platinum-based chemotherapy and 26 previously untreated patients [62]. An abstract presented at the ASCO Annual Meeting in 2020 reported an ORR of $61 \%$ in previously treated patients and $73 \%$ in treatment-naïve patients receiving pralsetinib for advanced NSCLC. The most common AEs reported with pralsetinib included constipation (35\%), hypertension $(28 \%)$, fatigue $(35 \%)$, musculoskeletal pain (32\%), diarrhea (24\%), cough (23\%), edema (20\%), and pyrexia (20\%) [60].

\subsection{Kirsten Rat Sarcoma Viral Oncogene Homolog (KRAS)}

$K R A S$ is the most frequently mutated oncogene in human cancers and is present in approximately $20 \%$ to $30 \%$ of NSCLC adenocarcinoma tumors [12,63]. KRAS encodes for a guanosine triphosphatase that cycles between an active and inactive state to regulate cell 
signal transduction. Somatic KRAS mutations result in constitutive activation of guanine nucleotide-binding proteins, which activates downstream signaling and leads to uncontrolled cell proliferation and survival [64]. Historically, the presence of a KRAS mutation is associated with poor outcomes. KRAS mutations are associated with resistance to currently available targeted and platinum-based therapies; however, some subgroups of patients with $K R A S$ mutations may benefit from anti-PD-L1 immunotherapies [63]. KRAS mutations are more frequently observed in patients who smoke, males, Whites, and those of African ancestry compared with females and patients of Asian ancestry. KRAS mutations can be detected by RT-PCR and NGS; they are typically mutually exclusive with other driver mutations [12].

Currently, there are no KRAS inhibitors approved by the FDA for any malignancy. Sotorasib, a small-molecule tyrosine kinase inhibitor (TKI) that selectively binds to the $K R A S$, recently received breakthrough therapy designation from the FDA and a new drug application has been submitted through the FDA's Real-Time Oncology Review pilot program $[65,66]$. A phase 1 , multicenter, open-label trial of sotorasib enrolled 59 patients with NSCLC harboring the KRAS p.G12C mutation, a KRAS mutation observed in approximately $13 \%$ of NSCLCs [63]. All patients with NSCLC had received prior platinumbased chemotherapy and $90 \%$ had received anti-PD-1 or anti-PD-L1 therapy. After a median follow-up of 11.7 months, one-third of patients with NSCLC treated with sotorasib had a confirmed response and $88 \%$ of patients had disease control. The median PFS for all patients with NSCLC was 6.3 months. Patients with KRAS p.G12C, KRAS wildtype, and other KRAS mutations have similar clinical features, treatment, and survival; however, the potential of an actionable mutation for the KRAS p.G12C mutation may improve outcomes in this subgroup [67]. Phase 2 results from the CodeBreaK 100 clinical study, evaluating sotorasib in 126 patients with KRAS G12C-mutant advanced NSCLC, were presented at the IASLC 2020 World Conference on Lung Cancer in January 2021. Sotorasib showed an objective response rate (ORR) and disease control rate (DCR) of $37.1 \%$ and $80.6 \%$, respectively, with a median duration of response of 10 months [65].

Gastrointestinal toxicities including diarrhea, nausea, vomiting, and abdominal pain, often associated with TKI therapy, were observed in approximately one-third of patients in the sotorasib phase 1 study. Other common AEs in patients receiving sotorasib include fatigue (23\%) and elevations of aminotransferase levels (12\%-13\% of patients) [63].

\section{Emerging Biomarkers}

$M E T$ amplification is both a primary driver mutation and a pathway identified in resistance to EGFR TKIs [39]. De novo MET amplification occurs in $2 \%$ to $4 \%$ of patients with newly diagnosed, metastatic NSCLC and is associated with poor outcomes. Currently, the definition of high-level MET amplification is unclear because different investigators define it differently [68]. In a phase 1 study of 40 patients categorized as low, medium, or high $M E T$ amplification, crizotinib was associated with a $40 \%$ response rate in patients with high levels of MET amplification [69]. Similarly, a phase 1 study of 55 patients with MET-dysregulated NSCLC reported an ORR of $47 \%$ in the group of patients with the highest gene copy number of MET [70]. Capmatinib and crizotinib are endorsed by the NCCN guidelines panel for use in patients with NSCLC with high-level MET amplification [14]. 
The ERBB2 (HER2) biomarker is well established in breast cancer; however, the role in NSCLC is still being evaluated. ERBB2 exon 20 mutation occurs in $2 \%$ to $9 \%$ of NSCLC adenocarcinoma tumors. Current literature suggests more benefit with the combination of monoclonal antibodies targeting ERBB2 and chemotherapy or ERBB2 antibody-drug conjugates than with ERBB2-targeted TKIs [39]. In a phase 2 basket trial, 18 patients with advanced NSCLC with ERBB2 mutations received ado-trastuzumab emtansine [71]. The investigators observed an ORR of $44 \%$ with ado-trastuzumab emtansine and a median PFS of 5 months; toxicities included myelosuppression, infusion reactions, and elevated liver enzymes. A phase 2 trial of 42 patients with NSCLC with ERBB2 overexpression or an $E R B B 2$-activating mutation reported an ORR of $62 \%$ in patients receiving fam-trastuzumab deruxtecan with an estimated PFS of 14 months. Myelosuppression was a frequent AE in patients receiving fam-trastuzumab deruxtecan and $12 \%$ of patients presented with drugrelated interstitial lung disease [72]. Ado-trastuzumab emtansine and fam-trastuzumab deruxtecan are recommended by the NCCN Guidelines for patients with ERBB2 (HER2) mutations [73].

\section{The Role of the Pharmacist}

Like many other cancers, knowledge of the pathobiology of NSCLC is shifting treatment away from traditional cytotoxic chemotherapy to a more targeted approach [74]. With that, more patients are being managed at home and are being evaluated less frequently in the clinic. In general, transitioning more patients to targeted therapies is a positive change; however, it has revealed new gaps in the current cancer care delivery model for educating and monitoring patients. Oral targeted therapy management is complex given the fragmentation of care, the cost of therapy, tolerability and safety of medications, issues related to patient access, patient education, patient self-care management, and the monitoring and follow-up in the oncology patient population [75]. Also, patients and caregivers must be educated on the safe handling and disposal of oral oncolytic [76].

As the treatment of NSCLC becomes increasingly biomarker-driven, pharmacists must have a thorough understanding of the clinical impact that genetic mutations have on NSCLC treatment and the various methods available for testing each of these actionable markers. Before dispensing medication or when encountering patients with NSCLC in the hospital or clinic setting, pharmacists should review mutation testing results to ensure the prescribed therapy is appropriate for that patient. Given that the cost of novel therapies typically exceeds $\$ 150,000$ per year, many patients will need support in the process of obtaining oral targeted therapies [77]. Pharmacists should be aware of the Patient Assistance \& Reimbursement Guide; a resource developed by the Association of Community Cancer Centers. The guide is updated annually as a resource to help patients alleviate the financial burden of their medications [78]. Table 3 outlines pharmacotherapy used in NSCLC [79, 80].

Table 3. Pharmacology of targeted therapy in NSCLC

\begin{tabular}{|l|l|l|l|l|}
\hline Biomarker & $\begin{array}{l}\text { Drug Generic } \\
\text { (Brand) }\end{array}$ & $\begin{array}{l}\text { Mechanism of } \\
\text { Action }\end{array}$ & $\begin{array}{l}\text { Dose and } \\
\text { Administration }\end{array}$ & $\begin{array}{l}\text { Notable Adverse } \\
\text { Effects }\end{array}$ \\
\hline $\boldsymbol{R E T}$ & $\begin{array}{l}\text { Cabozantinib } \\
\text { (Cabometyx) }\end{array}$ & $\begin{array}{l}\text { AXL, FLT-3, } \\
\text { KIT, MER, }\end{array}$ & $\begin{array}{l}60 \mathrm{mg} \text { once } \\
\text { daily }\end{array}$ & Hypertension \\
\hline
\end{tabular}


European Journal of Molecular \& Clinical Medicine

ISSN 2515-8260 Volume 08, Issue 03, 2021

\begin{tabular}{|c|c|c|c|c|}
\hline & & $\begin{array}{l}\text { MET, RET, } \\
\text { ROSI, } \\
\text { VEG FR-1-3 } \\
\text { inhibitor } \\
\end{array}$ & (Cabometyx) & \\
\hline & $\begin{array}{l}\text { Pralsetinib } \\
\text { (Gavreto) }\end{array}$ & $\begin{array}{l}\text { RET } \\
\text { inhibitor }\end{array}$ & $\begin{array}{l}400 \mathrm{mg} \text { once } \\
\text { daily on an } \\
\text { empty stomach }\end{array}$ & $\begin{array}{l}\text { - Hepatotoxicity } \\
\cdot \text { Hypertension } \\
\text { - Interstitinal } \\
\text { lung disease }\end{array}$ \\
\hline & $\begin{array}{l}\text { Selpercatinib } \\
\text { (Retevmo) }\end{array}$ & $\begin{array}{l}\text { RET, } \\
\text { FGFRl-3, } \\
\text { VEG FR1,3 } \\
\text { inhibitor }\end{array}$ & $\begin{array}{l}120 \mathrm{mg} \text { or } \\
160 \mathrm{mg} \\
\text { twice daily } \\
\text { with or } \\
\text { without food }\end{array}$ & $\begin{array}{l}\cdot \text { QTc } \\
\text { prolongation } \\
\cdot \text { Hepatotoxicity } \\
\cdot \text { Hypertension }\end{array}$ \\
\hline & $\begin{array}{l}\text { Vandetanib } \\
\text { (Caprelsa) }\end{array}$ & $\begin{array}{l}\text { EGFR, } \\
\text { VEGFR, } \\
\text { RET, } \\
\text { SRC } \\
\text { inhibitor }\end{array}$ & $\begin{array}{l}300 \mathrm{mg} \text { once daily } \\
\text { with or without } \\
\text { food }\end{array}$ & $\begin{array}{l}\text { - Corneal } \\
\text { changes } \\
\text { - Hepatotoxicity } \\
\text { - Hypertension } \\
\text { - Interstitial lung } \\
\text { disease } \\
\text { - QTc } \\
\text { prolongation }\end{array}$ \\
\hline \multirow{3}{*}{ METex 14} & $\begin{array}{l}\text { Capmatinib } \\
\text { (Tabrecta) }\end{array}$ & $\begin{array}{l}\text { MET } \\
\text { inhibitor }\end{array}$ & $\begin{array}{l}400 \mathrm{mg} \text { twice } \\
\text { daily with or } \\
\text { without food }\end{array}$ & $\begin{array}{l}\cdot \text { Hepatotoxicity } \\
\cdot \text { Interstitial } \\
\text { lung disease }\end{array}$ \\
\hline & $\begin{array}{l}\text { Crizotinib } \\
\text { (Xalkori) }\end{array}$ & $\begin{array}{l}\text { ALK, ROS1, } \\
\text { MET } \\
\text { inhibitor }\end{array}$ & $\begin{array}{l}250 \mathrm{mg} \text { twice } \\
\text { daily with or } \\
\text { without food }\end{array}$ & $\begin{array}{l}\text { - Bradycardia } \\
\cdot \text { Hepatotoxicity } \\
\text { - Interstitial } \\
\text { lung disease } \\
\cdot \text { QTc } \\
\text { prolongation } \\
\text { - Visual } \\
\text { disturbances }\end{array}$ \\
\hline & $\begin{array}{l}\text { Tepotinib } \\
\text { (Tepmetko) }\end{array}$ & $\begin{array}{l}\text { MET } \\
\text { inhibitor }\end{array}$ & $\begin{array}{l}450 \mathrm{mg} \text { once } \\
\text { daily with food }\end{array}$ & $\begin{array}{l}\text { - Hepatotoxicity } \\
\text { - Interstitial lung } \\
\text { disease }\end{array}$ \\
\hline NTRK & $\begin{array}{l}\text { Entrectinib } \\
\text { (Rozlytrek) }\end{array}$ & $\begin{array}{l}\text { ALK, ROSl, } \\
\text { TRK } \\
\text { inhibitor }\end{array}$ & $\begin{array}{l}600 \mathrm{mg} \text { once daily } \\
\text { with or without } \\
\text { food }\end{array}$ & $\begin{array}{l}\cdot \text { Edema } \\
\cdot \text { Hepatotoxicity } \\
\cdot \text { Neurotoxicity } \\
\cdot \text { QTc } \\
\text { prolongation } \\
\cdot \text { Visual } \\
\text { disturbances }\end{array}$ \\
\hline
\end{tabular}




\begin{tabular}{|l|l|l|l|l|}
\hline & $\begin{array}{l}\text { Larotrectinib } \\
\text { (Vitrakvi) }\end{array}$ & $\begin{array}{l}\text { TRK } \\
\text { inhibitor }\end{array}$ & $\begin{array}{l}100 \mathrm{mg} \text { twice daily } \\
\text { with or without } \\
\text { food }\end{array}$ & $\begin{array}{l}\text { - Hepatotoxicity } \\
\cdot \text { Neurotoxicity }\end{array}$ \\
\hline
\end{tabular}

The Quality Oncology Practice Initiative (QOPI) program standards for certification require documentation of the patients' ability to adhere to chemotherapy administered outside of the health care setting and to assess chemotherapy adherence at defined meaningful intervals [81]. Patient counseling and symptom management are services that a pharmacist can provide that fulfill multiple QOPI measures and may be eligible for reimbursement via the CMS Merit-Based Incentive Payment System [82]. Retrospective analyses of pharmacist-led, collaborative patient education and AE management in patients with NSCLC in communitybased oncology settings have demonstrated AEs of a TKI could be successfully managed by the pharmacist and were associated with low rates of discontinuing therapy because of AEs [83, 84]. Patients were contacted regularly by phone and encouraged to use prescribed medications or over-the-counter products to manage symptoms. Pharmacists contacted the provider if they felt a patient needed additional evaluation or medication. An excellent resource for counseling patients about oral chemotherapy is the Oral Chemotherapy Education Medication Sheets, which are updated frequently [85].

In general, TKIs are hepatically metabolized and subject to drug-drug interactions (DDIs) mediated by cytochrome P450 3A4. DDIs have been reported in $23 \%$ to $78 \%$ of patients receiving cancer therapy, with potential outcomes including both therapeutic failure and increased toxicity $[86,87]$. Pharmacists must ensure they obtain comprehensive and accurate information from patients on the use of other medications and natural products to ensure patient safety and optimal drug therapy [88].

\section{Conclusion}

Pharmacists across the health care spectrum are involved in the transition of cancer therapy to personalized medicine with therapies specifically targeted to the oncogenic pathway of the tumor. Ensuring the right patient receives the right targeted therapy, at the right dose, at the right time, and via the right method of administration is essential to optimizing outcomes for patients with NSCLC with driver mutations. Managing DDIs and AEs, mitigating financial toxicity, facilitating access to medications, and improvements in medication adherence are key roles pharmacists serve in the management of patients with NSCLC. On-going research into novel biomarkers and effective targeted therapies is expected to further improve outcomes for patients with NSCLC.

\section{References}

1. Siegel, R.L., K.D. Miller, and A. Jemal, Cancer statistics, 2016. CA: a cancer journal for clinicians, 2016. 66(1): p. 7-30.

2. Krist, A.H., et al., Screening for lung cancer: US preventive services task force recommendation statement. JAMA, 2021. 325(10): p. 962-970.

3. Ettinger, D.S., et al., Non-small cell lung cancer, version 5.2017, NCCN clinical practice guidelines in oncology. Journal of the National Comprehensive Cancer Network, 2017. 15(4): p. 504-535. 
4. Chen, J., et al., Genomic landscape of lung adenocarcinoma in East Asians. Nature genetics, 2020. 52(2): p. 177-186.

5. Giustini, N.P., et al., Advances in Treatment of Locally Advanced or Metastatic NonSmall Cell Lung Cancer: Targeted Therapy. Clinics in chest medicine, 2020. 41(2): p. 223-235.

6. Goldstraw, P., et al., Non-small-cell lung cancer. The Lancet, 2011. 378(9804): p. 1727-1740.

7. Bodor, J.N., Y. Boumber, and H. Borghaei, Biomarkers for immune checkpoint inhibition in non-small cell lung cancer (NSCLC). Cancer, 2020. 126(2): p. 260-270.

8. Network, N.C.C., NCCN Clinical Practice Guidelines in Oncology (NCCN Guidelines®): Non-small Cell Lung Cancer, version 6. 2020.

9. VanderLaan, P.A., D. Rangachari, and D.B. Costa, The rapidly evolving landscape of biomarker testing in non-small cell lung cancer. Cancer cytopathology, 2021. 129(3): p. 179.

10. Pisapia, P., et al., Predictive biomarkers for molecular pathology in lung cancer. 2020, Future Medicine.

11. Smeltzer, M.P., et al., The International Association for the Study of Lung Cancer global survey on molecular testing in lung cancer. Journal of Thoracic Oncology, 2020. 15(9): p. 1434-1448.

12. Lindeman, N.I., et al., Updated molecular testing guideline for the selection of lung cancer patients for treatment with targeted tyrosine kinase inhibitors: guideline from the College of American Pathologists, the International Association for the Study of Lung Cancer, and the Association for Molecular Pathology. Archives of pathology \& laboratory medicine, 2018. 142(3): p. 321-346.

13. Goulart, B.H., et al., Access to Tyrosine Kinase Inhibitors and Survival in Patients with Advanced EGFR+ and ALK+ Positive Non-small-cell Lung Cancer Treated in the Real-World. Clinical Lung Cancer, 2021.

14. Ettinger, D.S., et al., NCCN Guidelines Insights: Non-Small Cell Lung Cancer, Version 2.2021: Featured Updates to the NCCN Guidelines. Journal of the National Comprehensive Cancer Network, 2021. 19(3): p. 254-266.

15. Pennell, N.A., et al., Biomarker testing for patients with advanced non-small cell lung cancer: real-world issues and tough choices. American Society of Clinical Oncology Educational Book, 2019. 39: p. 531-542.

16. Zheng, R., et al., Molecular profiling of key driver genes improves staging accuracy in multifocal non-small cell lung cancer. The Journal of thoracic and cardiovascular surgery, 2020. 160(2): p. e71-e79.

17. Gao, D., et al., Molecular and clinicopathological characteristics of Chinese nonsmall cell lung cancers with ROS1 gene fusions identified by next-generation sequencing. 2020, AACR.

18. D'Haene, N., et al., Clinical validation of targeted next generation sequencing for colon and lung cancers. PloS one, 2015. 10(9): p. e0138245.

19. Tafe, L.J., et al., Clinical genotyping of non-small cell lung cancers using targeted next-generation sequencing: utility of identifying rare and co-mutations in oncogenic driver genes. Neoplasia, 2016. 18(9): p. 577-583. 
20. Yang, Y., et al., Molecular findings among patients referred for clinical whole-exome sequencing. Jama, 2014. 312(18): p. 1870-1879.

21. Bernard, P.S. and C.T. Wittwer, Real-time PCR technology for cancer diagnostics. Clinical chemistry, 2002. 48(8): p. 1178-1185.

22. Watanabe, T., et al., Comparison of lung cancer cell lines representing four histopathological subtypes with gene expression profiling using quantitative real-time PCR. Cancer cell international, 2010. 10(1): p. 1-12.

23. Schmidt, K.T., et al., Precision oncology medicine: the clinical relevance of patientspecific biomarkers used to optimize cancer treatment. The Journal of Clinical Pharmacology, 2016. 56(12): p. 1484-1499.

24. McEvoy, A.C., et al., Droplet digital PCR for mutation detection in formalin-fixed, paraffin-embedded melanoma tissues: a comparison with sanger sequencing and pyrosequencing. The Journal of Molecular Diagnostics, 2018. 20(2): p. 240-252.

25. Yatabe, Y., et al., Best practices recommendations for diagnostic immunohistochemistry in lung cancer. Journal of Thoracic Oncology, 2019. 14(3): p. 377-407.

26. Thunnissen, E., et al., The use of immunohistochemistry improves the diagnosis of small cell lung cancer and its differential diagnosis. An international reproducibility study in a demanding set of cases. Journal of Thoracic Oncology, 2017. 12(2): p. 334346.

27. John, A., B. Yang, and R. Shah, Clinical Impact of Adherence to NCCN Guidelines for Biomarker Testing and First-Line Treatment in Advanced Non-Small Cell Lung Cancer (aNSCLC) Using Real-World Electronic Health Record Data. Advances in therapy, 2021. 38(3): p. 1552-1566.

28. Wright, W.F., et al., Progress Report: Next-Generation Sequencing (NGS), Multiplex Polymerase Chain Reaction (PCR), and Broad-Range Molecular Assays as Diagnostic Tools for Fever of Unknown Origin (FUO) Investigations in Adults. Clinical Infectious Diseases, 2021.

29. Hayes, D.F., Defining Clinical Utility of Tumor Biomarker Tests: A Clinician's Viewpoint. Journal of Clinical Oncology, 2021. 39(3): p. 238-248.

30. Hassan, E.M. and M.C. DeRosa, Recent advances in cancer early detection and diagnosis: Role of nucleic acid based aptasensors. TrAC Trends in Analytical Chemistry, 2020. 124: p. 115806.

31. Food and D. Administration, Oncomine ${ }^{\mathrm{TM}}$ Dx Target Test Part I: Sample Preparation and Quantification User Guide. Revision C. 0 2017. 2018.

32. Lisberg, A. and E.B. Garon, Does Platinum-Based Chemotherapy Still Have a Role in First-Line Treatment of Advanced Non-Small-Cell Lung Cancer? Journal of clinical oncology, 2019. 37(7): p. 529-536.

33. Hanna, N.H., et al., Therapy for stage IV non-small-cell lung cancer without driver alterations: $A S C O$ and $\mathrm{OH}(\mathrm{CCO})$ joint guideline update. Journal of Clinical Oncology, 2020.

34. Mason, C., et al., Patterns of biomarker testing rates and appropriate use of targeted therapy in the first-line, metastatic non-small cell lung cancer treatment setting. Journal of clinical pathways: the foundation of value-based care, 2018. 4(1): p. 49. 
35. Ma, R., et al., Serum Platelet-Derived Growth Factor Is Significantly Lower in Patients with Lung Cancer and Continued to Decrease After Platinum-Based Chemotherapy. OncoTargets and therapy, 2020. 13: p. 1883.

36. Feng, B., et al., Non-small-cell lung cancer and miRNAs: novel biomarkers and promising tools for treatment. Clinical science, 2015. 128(10): p. 619-634.

37. Kalemkerian, G.P., et al., Molecular testing guideline for the selection of patients with lung cancer for treatment with targeted tyrosine kinase inhibitors: American society of clinical oncology endorsement of the college of american pathologists/international association for the study of lung cancer/association for molecular pathology clinical practice guideline update. Journal of clinical oncology: official journal of the American Society of Clinical Oncology, 2018. 36(9): p. 911.

38. Huang, C., et al., Management of non-small cell lung cancer patients with MET exon 14 skipping mutations. Current treatment options in oncology, 2020. 21(4): p. 1-15.

39. Chu, Q.S., Targeting non-small cell lung cancer: driver mutation beyond epidermal growth factor mutation and anaplastic lymphoma kinase fusion. Therapeutic advances in medical oncology, 2020. 12: p. 1758835919895756.

40. Fujino, T., K. Suda, and T. Mitsudomi, Emerging MET tyrosine kinase inhibitors for the treatment of non-small cell lung cancer. Expert Opinion on Emerging Drugs, 2020. 25(3): p. 229-249.

41. Statements, F.-L., Incyte Announces FDA Approval of Tabrecta ${ }^{\mathrm{TM}}$ (capmatinib) for the Treatment of Patients with Metastatic Non-Small Cell Lung Cancer with METex14.

42. Wolf, J., et al., Capmatinib in MET Exon 14-Mutated or MET-Amplified Non-SmallCell Lung Cancer. New England Journal of Medicine, 2020. 383(10): p. 944-957.

43. Jørgensen, J.T., The current landscape of the FDA approved companion diagnostics. Translational Oncology, 2021. 14(6): p. 101063.

44. Drilon, A., et al., Antitumor activity of crizotinib in lung cancers harboring a MET exon 14 alteration. Nature medicine, 2020. 26(1): p. 47-51.

45. Kluetz, P.G., et al., FDA Oncology Center of Excellence Project Renewal: Engaging the Oncology Community to Update Product Labeling for Older Oncology Drugs. Clinical Cancer Research, 2021. 27(4): p. 916-921.

46. Paik, P.K., et al., Tepotinib in non-small-cell lung cancer with MET exon 14 skipping mutations. New England Journal of Medicine, 2020. 383(10): p. 931-943.

47. Felip, E., et al., Tepotinib in patients with advanced non-small cell lung cancer (NSCLC) harboring MET exon 14-skipping mutations: phase II trial. J Clin Oncol, 2018. 36(15_suppl): p. 9016.

48. Oxnard, G., et al., TATTON: a multi-arm, phase Ib trial of osimertinib combined with selumetinib, savolitinib, or durvalumab in EGFR-mutant lung cancer. Annals of Oncology, 2020. 31(4): p. 507-516.

49. Drilon, A., et al., Efficacy of larotrectinib in TRK fusion-positive cancers in adults and children. New England Journal of Medicine, 2018. 378(8): p. 731-739.

50. Matter, M.S., et al., Narrative review of molecular pathways of kinase fusions and diagnostic approaches for their detection in non-small cell lung carcinomas. Translational Lung Cancer Research, 2020. 9(6): p. 2645. 
51. Dunn, D.B., Larotrectinib and Entrectinib: TRK Inhibitors for the Treatment of Pediatric and Adult Patients With NTRK Gene Fusion. Journal of the Advanced Practitioner in Oncology, 2020. 11(4): p. 418.

52. Thompson, J.A., et al., NCCN Guidelines Insights: Management of ImmunotherapyRelated Toxicities, Version 1.2020: Featured Updates to the NCCN Guidelines. Journal of the National Comprehensive Cancer Network, 2020. 18(3): p. 230-241.

53. Roviello, G., et al., TRK fusion positive cancers: From first clinical data of a TRK inhibitor to future directions. Critical Reviews in Oncology/Hematology, 2020: p. 103011.

54. Jørgensen, J.T., Site-agnostic biomarker-guided oncology drug development. Expert review of molecular diagnostics, 2020. 20(6): p. 583-592.

55. Doebele, R.C., et al., Entrectinib in patients with advanced or metastatic NTRK fusion-positive solid tumours: integrated analysis of three phase 1-2 trials. The Lancet Oncology, 2020. 21(2): p. 271-282.

56. Liu, D., et al., Characterization of on-target adverse events caused by TRK inhibitor therapy. Annals of Oncology, 2020. 31(9): p. 1207-1215.

57. Drilon, A., et al., Efficacy of selpercatinib in RET fusion-positive non-small-cell lung cancer. New England Journal of Medicine, 2020. 383(9): p. 813-824.

58. DRIVER, S.A.G., C.O. CARBOPLATINO, and I.R.D.T. DI MANTENIMENTO, NSCLC stadio iv-Prima Linea.

59. Balogh, E.P., et al., Challenges and Opportunities to Updating Prescribing Information for Longstanding Oncology Drugs. The oncologist, 2020. 25(3): p. e405.

60. Markham, A., Pralsetinib: First Approval. Drugs, 2020: p. 1-6.

61. Food and D. Administration, List of cleared or approved companion diagnostic devices (in vitro and imaging tools). Availabe online: https://www. fda. gov/medicaldevices/vitro-diagnostics/list-cleared-or-approved-companion-diagnostic-d evicesvitro-and-imaging-tools (accessed on 3 January 2020), 2019.

62. Gainor, J.F., et al., Registrational dataset from the phase I/II ARROW trial of pralsetinib (BLU-667) in patients (pts) with advanced RET fusion+ non-small cell lung cancer (NSCLC). 2020, American Society of Clinical Oncology.

63. Hong, D.S., et al., KRASG12C inhibition with sotorasib in advanced solid tumors. New England Journal of Medicine, 2020. 383(13): p. 1207-1217.

64. Nacchio, M., et al., KRAS mutations testing in non-small cell lung cancer: The role of Liquid biopsy in the basal setting. Journal of Thoracic Disease, 2020. 12(7): p. 3836.

65. Timmins, P., The latest developments in the field of therapeutic delivery, December 2020. Therapeutic Delivery, 2021(0).

66. Mok, T., S. Peters, and D. Camidge, Outcomes According to ALK Status Determined by Central IHC or FISH in Patients with ALK-Positive NSCLC Enrolled in the Phase III ALEX Study. J Thorac Oncol, 2020. 1556: p. 30815-7.

67. Cui, W., et al., Real world outcomes in KRAS G12C mutation positive non-small cell lung cancer. Lung Cancer, 2020. 146: p. 310-317.

68. Gu, Z.-B., et al., Patient with EGFR-mutant lung cancer harboring de novo MET amplification successfully treated with gefitinib combined with crizotinib. Current Problems in Cancer, 2021: p. 100702. 
69. Camidge, D.R., et al., Crizotinib in patients (pts) with MET-amplified non-small cell lung cancer (NSCLC): Updated safety and efficacy findings from a phase 1 trial. 2018, American Society of Clinical Oncology.

70. Schuler, M., et al., Molecular correlates of response to capmatinib in advanced nonsmall-cell lung cancer: clinical and biomarker results from a phase I trial. Annals of Oncology, 2020. 31(6): p. 789-797.

71. Li, B.T., et al., Ado-trastuzumab emtansine for patients with HER2-mutant lung cancers: results from a phase II basket trial. Journal of Clinical Oncology, 2018. 36(24): p. 2532.

72. Smit, E.F., et al., Trastuzumab deruxtecan (T-DXd; DS-8201) in patients with HER2mutated metastatic non-small cell lung cancer (NSCLC): Interim results of DESTINYLung01. 2020, American Society of Clinical Oncology.

73. Azghadi, S. and M.E. Daly, Radiation and immunotherapy combinations in non-small cell lung cancer. Cancer Treatment and Research Communications, 2021. 26: p. 100298.

74. Ma, C.S., Role of pharmacists in optimizing the use of anticancer drugs in the clinical setting. Integrated Pharmacy Research and Practice, 2014. 3: p. 11-24.

75. Mackler, E., et al., 2018 hematology/oncology pharmacist association best practices for the management of oral oncolytic therapy: pharmacy practice standard. Journal of oncology practice, 2019. 15(4): p. e346-e355.

76. Goodin, S., et al., Safe handling of oral chemotherapeutic agents in clinical practice: recommendations from an international pharmacy panel. Journal of Oncology Practice, 2011. 7(1): p. 7-12.

77. DeMartino, P.C., M.D. Miljković, and V. Prasad, Potential cost implications for All US Food and drug administration oncology drug approvals in 2018. JAMA Internal Medicine, 2021. 181(2): p. 162-167.

78. Patient Assistance and Reimbursement Guide. 2020 January 2021 [cited 2021 February 25th]; Available from: https://www.accccancer.org/home/learn/publications/patient-assistance-and-reimbursement-guide.

79. Suda, K. and T. Mitsudomi, Emerging oncogenic fusions other than ALK, ROS1, RET, and NTRK in NSCLC and the role of fusions as resistance mechanisms to targeted therapy. Translational Lung Cancer Research, 2020. 9(6): p. 2618.

80. Dong, J., et al., Advances in targeted therapy and immunotherapy for non-small cell lung cancer based on accurate molecular typing. Frontiers in pharmacology, 2019. 10: p. 230.

81. QOPI Certification Program Standards. 2020 [cited 2021 March 25th]; Available from: $\quad$ https://practice.asco.org/sites/default/files/drupalfiles/201912/QOPI\%20Certification\%20Standards\%20January\%202020.pdf.

82. Vulaj, V., et al., Oncology pharmacist opportunities: closing the gap in quality care. Journal of oncology practice, 2018. 14(6): p. e403-e411.

83. Cheema, P.K., et al., Multi-disciplinary proactive follow-up algorithm for patients with advanced NSCLC receiving afatinib. Supportive Care in Cancer, 2019. 27(3): p. 1029-1039. 


\section{European Journal of Molecular \& Clinical Medicine}

ISSN 2515-8260 Volume 08, Issue 03, 2021

84. Khrystolubova, N., et al., Pharmacist-led patient education and adverse event management in patients with non-small cell lung cancer receiving afatinib in a community-based, real-world clinical setting. Journal of Oncology Pharmacy Practice, 2020. 26(1): p. 13-22.

85. Huff, C., Oral Chemotherapy: A home safety educational framework for healthcare providers, patients, and caregivers. Clinical journal of oncology nursing, 2020. 24(1).

86. Bowlin, S.J., et al. Twelve-month frequency of drug-metabolizing enzyme and transporter-based drug-drug interaction potential in patients receiving oral enzymetargeted kinase inhibitor antineoplastic agents. in Mayo Clinic Proceedings. 2013. Elsevier.

87. Ismail, M., et al., Prevalence and significance of potential drug-drug interactions among cancer patients receiving chemotherapy. BMC cancer, 2020. 20: p. 1-9.

88. LM, H. Further defining the scope of hematology/oncology pharmacy practice. 2019 [cited 2021 25th]; Available from: https://www.hoparx.org/images/hopa/resource-library/guidelinesstandards/HOPA18_Scope-2_Web2.pdf. 